\title{
Theoretical study of anion carriers based on trifluoroacetophenone
}

\section{Journal Article}

\section{Author(s):}

Inglis, Janice M.; Ha, Tae-Kyu

Publication date:

1997

Permanent link:

https://doi.org/10.3929/ethz-b-000423049

Rights / license:

In Copyright - Non-Commercial Use Permitted

Originally published in:

Structural Chemistry 8(2), https://doi.org/10.1007/BF02262846 


\title{
Theoretical Study of Anion Carriers Based on Trifluoroacetophenone
}

\author{
Janice M. Inglis ${ }^{1,2}$ and Tae-Kyu $\mathrm{Ha}^{1}$
}

Received January 22, 1996; revised July 8, 1996; accepted July 15, 1996

Model calculations on anion carrier ligands related to trifluoroacetophenone were carried out using the semiempirical AM1 method in order to investigate the factors involved in such anion-ligand complexation. The reaction of halogen derivatives of acetophenone with various nucleophiles such as water, carbonic acid, and bicarbonate anion was studied. By this means, the effect of various structural changes, such as variation of the ring substituents and variation of the degree and type of halogen atom substitution, could be determined. It is shown that in terms of relative stability, fluorine derivatives are preferable to chlorine derivatives for the binding of water and carbonic acid. Monosubstitution of a methoxy group in the ortho position of the trifluoroacetophenone ring also brought about stability in the case of the hydration reaction. An electron-withdrawing ester group in the para position on the trifluoroacetophenone ring brings about stabilization also.

KEY WORDS: AM1; trifluoroacetophenone; semiempirical; anion carrier ligands.

\section{INTRODUCTION}

The carbonate-selective electrode of Meyerhoff [1] utilizes quaternary ammonium salts in conjunction with trifluoroacetophenone derivatives such as trifluoroacetyl-p-butylbenzene (TFABB). Meyerhoff and co-workers [1] investigated the mechanism and demonstrated by UV absorption and ${ }^{13} \mathrm{C}-\mathrm{NMR}$ spectroscopy that carbonate anions interact reversibly, via nucleophilic attack, with the carbonyl carbon atom of TFABB to form lipophilic carbonate complexes (cf Scheme 1). This mechansim was further substantiated by Behringer $e t a l$. [2].

In the present work, ligands selective for carbonate anions have been investigated in order to gain a clearer understanding of the factors involved in such interactions. It was anticipated that this would provide an aid in the design of new ionophores suitable for application as ion-selective electrodes or in eliminating useless can-

\footnotetext{
'Department of Chemistry, Swiss Federal Institute of Technology (ETH), ETH-Zentrum, Zurich, Switzerland.

${ }^{2}$ Correspondence should be directed to Janice $M$. Inglis, Department of Pharmacy, Swiss Federal Institute of Technology (ETH), Technopark, Technoparkstr. 1, 8005 Zurich, Switzerland.
}

didate ionophores before their synthesis in the laboratory.

The influence of structural changes on the free energy of the gas-phase reaction of these halogen derivatives of acetophenone was roughly estimated by calculating the difference of the total energies of the product and the reactants. Since extensive structural optimizations were involved and the molecules were relatively large, the semiempirical AM1 method [3] was chosen in preference ab initio methods.

\section{DETAILS OF CALCULATIONS}

Optimization was carried out on the Vax using Version 1.0 of the AM1 program, which was part of the AMPAC package. In order to determine if the lowest energy conformer of the potential energy hypersurface was found by our optimization, a so-called "reaction coordinate study" was carried out for the structures. These were carried out in the first intance on the Vax and then later on the CRAY X-MP/28 with implementation of MOPAC Version 4.0 of the AM1 program, followed by reoptimization on the Vax for consistency. 

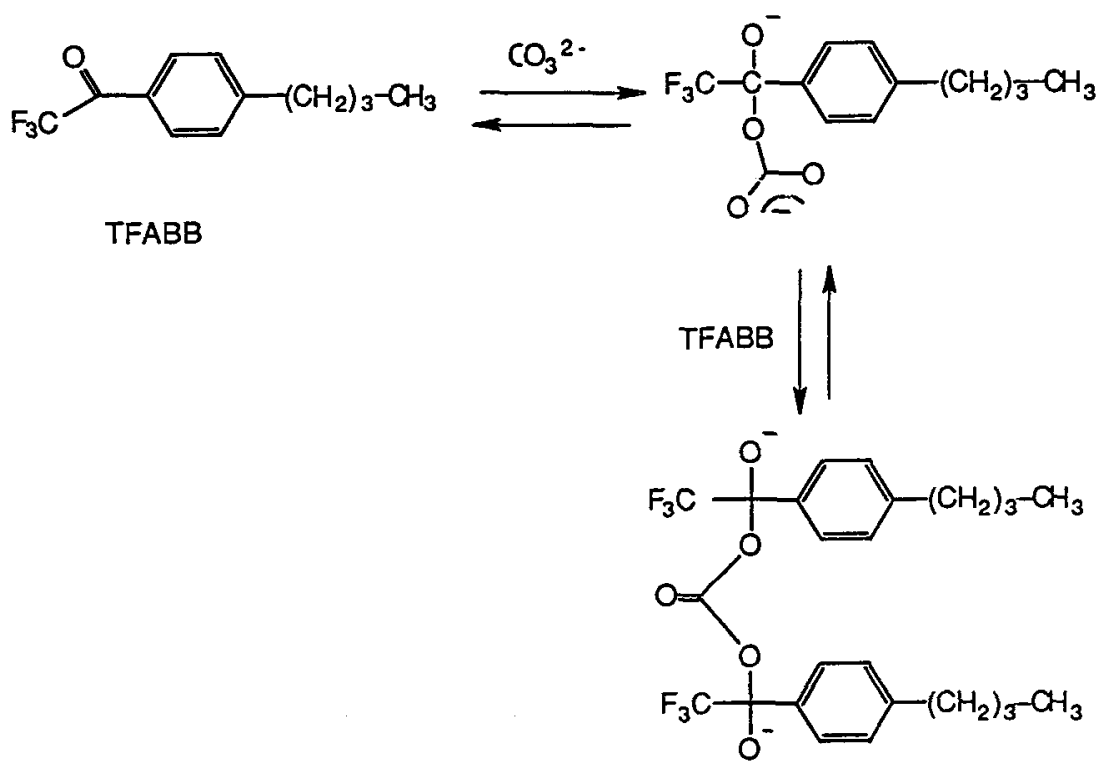

Scheme 1. Reaction of trifluoroacetyl-p-butylbenzene (TFABB) with carbonate dianion forming first a $1: 1$ complex. Reaction with a further molecule of TFABB gives a $2: 1$ complex [1, $2,7]$.

In each case, this was achieved by rotating about the $(\mathrm{XYZ}) \mathrm{C}-\mathrm{C}$ bond of the halogen derivatives of acetophenone or hydrated acetophenone. The dihedral angle of one of the atoms labeled $\mathrm{X}$ in the (XYZ)Cmoiety was varied at $30^{\circ}$ intervals through a full $360^{\circ}$ with respect to a carbon atom of the phenyl ring, starting with the optimized geometry, while all other geometrical variables in the molecule were optimized.

From this analysis, it was hoped that we could isolate and reoptimize those structures, for which it was obvious that the lowest energy conformer had not been found, that is, where the energy value we obtained from optimization was higher than the lowest minimum given by the reaction coordinate study or those which were unreasonable based on the symmetry of the structure in comparison with the reaction coordinate profile.

There are, however, dangers associated with this reaction coordinate method of attempting to locate the global minimum, besides the obvious one of looking only at a cross section of the energy hypersurface when we rotate about one dihedral angle. There is the problem that each point in this reaction coodinate path uses the geometry of the previous point as input. Thus a poor geometry at a certain dihedral angle can influence the later points on the pathway.

Because of these problems associated with the use of the reaction coordinate option to determine the global minimum, another strategy was employed in those examples which gave an unusual trajectory. In these cases, separate individual optimizations which we refer to as "manual optimizations" at $30 \mathrm{deg}$ intervals about the same dihedral angle as previously were carried out. The advantage of this is that the initial Vax optimized geometry is used as input at each point along the trajectory.

A close examination of the stationary points along the reaction path was prompted by the CNDO study of Mollendal [4] concerning the molecules of structure $\mathrm{YH}_{2} \mathrm{C}-\mathrm{CO}-\mathrm{X}$, where $\mathrm{Y}=\mathrm{Cl}$ or $\mathrm{F}$ and $\mathrm{X}=\mathrm{H}$ or $\mathrm{F}$ or $\mathrm{Cl}$, and their similarity with our structures. This work indicates the variation of the position of the global minimum depending on the halogen atom under consideration.

\section{RESULTS AND DISCUSSION}

Certain trifluoroacetophenones have been found to be selective for carbonate over other anions. The effect on the relative stability of the complex of varying both the number and type of halogen atoms present has been investigated. It was anticipated that this would provide an indication of the role of the halogen substituent. The effect of ortho and para ring substitution of trifluoroacetophenone has also been investigated. Increased relative stability of the complex may not, however, be reflected in increased selectivity of the ligand for a particular ion, since interaction must be reversible. Therefore, although a degree of relative stability is re- 
quired, too much stability will impair the reversibility of these reactions.

In order that a prediction of the relative stabilities of these derivatives could be made, it was necessary to compare the differences between reactants and products in total energy of the reactions discussed in the following sections. The behavior of fluorine compounds is in general still not well understood and there is a scarcity of information in the literature.

\section{Halogen Derivatives of Acetophenone and Hydrated Acetophenone}

Trifluoroacethylbenzene (TFAB) 1 was constructed on an Evans and Sutherland PS300 graphics terminal from templates in our template library using the molecular modeling program MOGLI. This was followed by AMl optimization. The $n$-butyl substituent in the para position of TFABB was omitted to reduce the number of degrees of freedom for reason of ease of calculation and because it had no influence on the investigation of the stability.

All halogen derivatives of acetophenone constructed used the fully optimized $\mathbf{I}$ as a starting structure with the appropriate halogen atom and bond length substitutions. Symmetry was not specified for the structures. Water, which is constant in each of the reactions (cf. Table I), gave a calculated heat of formation of $-247.9 \mathrm{~kJ} / \mathrm{mol}(-241.8 \mathrm{~kJ} / \mathrm{mol}$ [3] experimental) and a calculated total energy of $-33,631.1 \mathrm{~kJ} / \mathrm{mol}$.

With these halogen derivatives of acetophenone one would expect to see threefold or twofold symmetry (depending on the degree of substitution) in the pattern of the reaction coordinate profile of the total energy versus the dihedral angle. This is shown in Fig. 1 for TFAB 1 , which exhibits a very low torsional barrier, the differ-

Table I. Hydration Reaction of Halogen Derivatives of Acetophenone

\begin{tabular}{|c|c|c|c|}
\hline Substituent (XYZ)C- & Reactant & Reaction no. & Product \\
\hline $\mathrm{F}_{3} \mathrm{C}$ & $\mathbf{1}$ & 1 & 2 \\
\hline $\mathrm{HF}_{2} \mathrm{C}$ & 3 & 2 & 4 \\
\hline $\mathrm{H}_{2} \mathrm{FC}$ & 5 & 3 & 6 \\
\hline $\mathrm{H}_{3} \mathrm{C}$ & 7 & 4 & 8 \\
\hline $\mathrm{Cl}_{3} \mathrm{C}$ & 9 & 5 & 10 \\
\hline $\mathrm{HCl}_{2} \mathrm{C}$ & 11 & 6 & 12 \\
\hline $\mathrm{H}_{2} \mathrm{ClC}$ & 13 & 7 & 14 \\
\hline
\end{tabular}

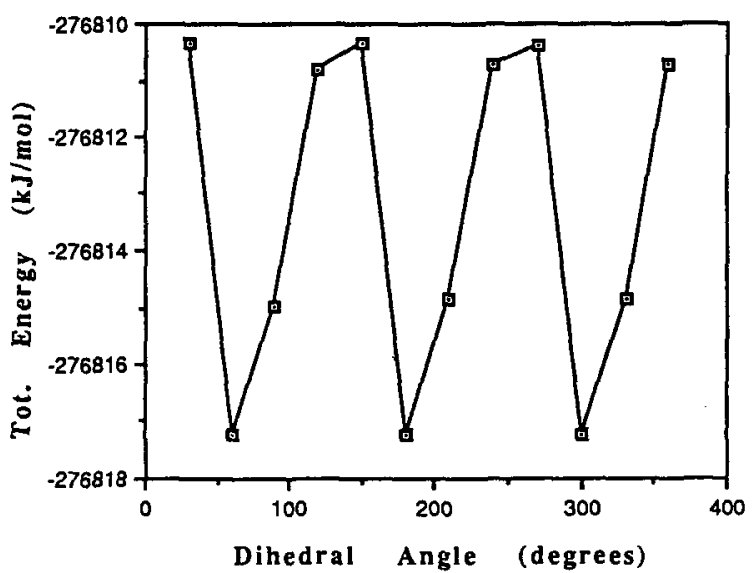

Fig. 1. Reaction coordinate profile of the total energy versus the dihedral angle for rotation about the $\mathrm{F}_{3} \mathrm{C}-\mathrm{C}$ bond of TFAB 1 .

ence between maxima and minima being less than $8 \mathrm{~kJ} /$ mol.

The stabilization afforded by conjugation of the carbonyl group with the phenyl ring was examined by rotation about the $\mathrm{CO}-\mathrm{Ph}$ bond in $10^{\circ}$ increments through a full $360^{\circ}$. This was achieved by means of the reaction coordinate option in the AM1 program, in which the carbonyl oxygen was the so-called reaction coordinate and its dihedral angle with respect to one of the phenyl carbon atoms was varied. All other coordinates were optimized. The reaction coordinate profile is shown in Fig. 2. Loss of conjugation accounted for 9.09 $\mathrm{kJ} / \mathrm{mol}$ when the carbonyl group was rotated $90^{\circ}$ out of the plane.

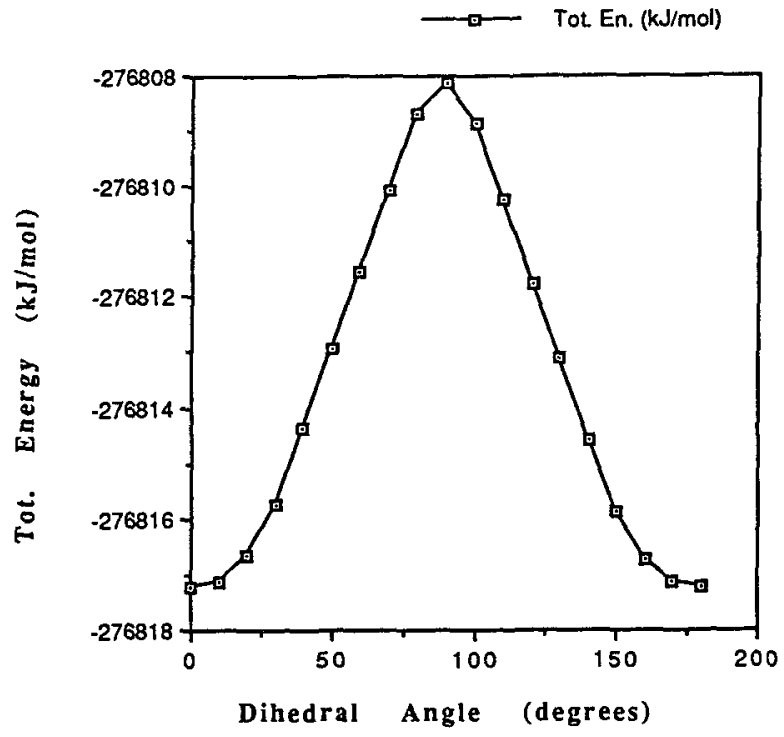

Fig. 2. Reaction coordinate profile for rotation about the $\mathrm{CO}-\mathrm{Ph}$ bond of TFAB 1 . 
Hydrated trifluoroacetophenone with an initial geometry in which one fluorine atom lies in the plane of the phenyl group and the remaining fluorines lie $+60^{\circ}$ and $-60^{\circ}$, respectively, above and below the plane with respect to the phenyl carbon was chosen as a starting conformation for optimization. This was derived from optimized TFAB 1 in which symmetry had been maintained and specified. In place of the carbonyl group, arbitrary coordinates for the hydroxy groups of $+60^{\circ}$ and $-60^{\circ}$ above and below the plane with respect to one of the phenyl carbon atoms were substituted. As for TFAB, the various halogen derivatives of the hydrated acetophenone were examined.

Looking at a Newman projection for 2 (cf. Fig. 3), we would expect the conformation in which the hydroxy groups and the phenyl are staggered with respect to the fluorines to be the most stable in terms of having the lowest energy. This appeared to be the case upon full optimization. Some degree of skewing was also observed. This is an example of symmetry being lowered (to $C_{1}$ ) with the AM1 potential, as our original structure was input with effective $C_{s}$ symmetry. The possibility that this geometry was some intermediate local minimum was investigated.

The results in Table II clearly show that there is increased relative stabilization of the products with the fluorine derivatives compared to those with chlorine. The degree of fluorine substitution appears to have very little effect on the total energy differences with our results. The chlorine derivatives also exhibited this trend.

It is now well known that fluorine substituted into various compounds leads to significant structural changes because of its high electronegativity and small size. Hildebrandt et al. [5] have found that there is a $\mathrm{C}-\mathrm{C}$ bond lengthening by $0.03-0.04 \AA$ in structures of the general type $\left(\mathrm{CF}_{3}\right)_{2} \mathrm{C}=\mathrm{X}$, where $\mathrm{X}$ represents an $\mathrm{O}, \mathrm{NH}$, or $\mathrm{CH}_{2}$ grouping. This we have also observed. In the case of acetophenone 7 , the optimized $\mathrm{C}-\mathrm{C}$ bond length we obtained for the $\mathrm{H}_{3} \mathrm{C}-\mathrm{C}$ moiety was 1.496 $\AA$, compared to that of $1.572 \AA$ for the trifluoro-derivative 1 .

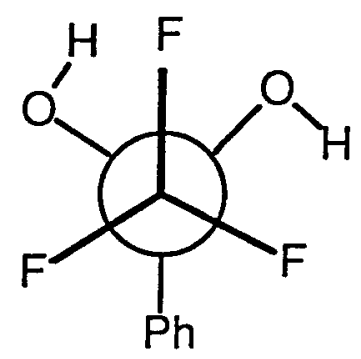

Fig. 3. Newman projection for hydrated trifluoroacetophenone 2.
Table II. AM1 Calculated Total Energy Differences (Between Products and Reactants) for the Reaction of Water with the Halogen Derivatives of Acetophenone

\begin{tabular}{clc}
\hline Reaction & Substituent & $\begin{array}{c}\text { Total energy difference } \\
\text { (products }- \text { reactants) } \\
(\mathrm{kJ} / \mathrm{mol})\end{array}$ \\
\hline 1 & $\mathrm{~F}_{3} \mathrm{C}-$ & -56.8 \\
2 & $\mathrm{~F}_{2} \mathrm{HC}-$ & -57.7 \\
3 & $\mathrm{FH}_{2} \mathrm{C}-$ & -56.2 \\
4 & $\mathrm{H}_{3} \mathrm{C}-$ & -43.9 \\
5 & $\mathrm{Cl}_{3} \mathrm{C}-$ & -45.0 \\
6 & $\mathrm{Cl}_{2} \mathrm{HC}-$ & -42.7 \\
7 & $\mathrm{ClH}_{2} \mathrm{C}-$ & -46.4 \\
\hline
\end{tabular}

The bond lengthening may result in a large energy change as indicated by the study of Bürgi and DublerSteudle [6] in their study of acetals. They found that $0.05 \AA$ of ground-state structural change can result in as much as a $10 \mathrm{kcal}$ change in free energy of activation.

These examples also illustrate the influence of initial geometry upon the final optimized geometry. If the conformation chosen as an initial geometry was that of a local minimum, then in general the overall global minimum will not be found. This was the case of our halogen derivatives of acetophenone, since it was optional which fluorine atom of optimized TFAB could be replaced by a hydrogen or chorine atom when constructing the Z-matrix. In each case the "odd" atom of the (XYZ)C - moiety was arbitrarily chosen to be that which lies at approximately $180^{\circ}$ with respect to the phenyl group when viewed along the $(\mathrm{XYZ}) \mathrm{C}-\mathrm{CO}$ bond in the $Z$-matrix of the optimized TFAB. For the monochloro-derivative 13 , this was the chlorine atom. In this example, this was not the lowest energy conformation and the overall global minimum was not initially found.

In the case of the fluorine derivatives, one has presumably predominantly a contribution from electronic interaction, whereas in the chlorine case, there is also steric interaction due to the larger size of the chlorine atom. This could account for the difference in conformation between the fluorine and chlorine derivatives of the most stable conformer.

\section{Reaction of the Halogen Derivatives of Acetophenone with Carbonic Acid}

Nucleophilic attack by carbonic acid on the carbonyl group of TFAB was investigated. This mechanism was substantiated by Meyerhoff [1]. The $1: 1$ adduct derivatives 15-21 were studied (cf. Table III).

As we saw with the halogen derivatives of aceto- 
Table III. Reaction of the Halogen Derivatives of Acetophenone with Carbonic Acid

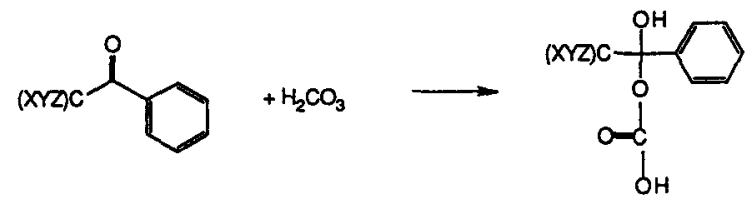

\begin{tabular}{cccc}
\hline Substituent $(X Y Z) C-$ & Reactant & Reaction no. & Product \\
\hline $\mathrm{F}_{3} \mathrm{C}$ & $\mathbf{1}$ & $\mathbf{8}$ & $\mathbf{1 5}$ \\
$\mathrm{HF}_{2} \mathrm{C}$ & $\mathbf{3}$ & 9 & $\mathbf{1 6}$ \\
$\mathrm{H}_{2} \mathrm{FC}$ & 5 & 10 & 17 \\
$\mathrm{H}_{3} \mathrm{C}$ & 7 & 11 & 18 \\
$\mathrm{Cl}_{3} \mathrm{C}$ & 9 & 12 & 19 \\
$\mathrm{HCl}_{2} \mathrm{C}$ & 11 & 13 & $\mathbf{2 0}$ \\
$\mathrm{H}_{2} \mathrm{ClC}$ & 13 & 14 & $\mathbf{2 1}$ \\
\hline
\end{tabular}

phenone, it was completely optional as to which fluorine atom of the $1: 1$ adduct optimize structure would be replaced by the appropriate hydrogen or chlorine atoms when constructing the Z-matrix. In each case the "odd" atom of the $(\mathrm{XYZ}) \mathrm{C}-$ moiety was arbitrarily chosen to lie at $41.5^{\circ}$ (the torsional angle of one fluorine atom of the optimized $\mathrm{F}_{3} \mathrm{C}$-derivative) with respect to the phenyl group.

The larger size of these derivatives in comparison with the previous structures discussed results in increased degrees of freedom. Therefore many conformations are possible. As a means of eliminating those conformations which clearly do not represent the most stable, reaction coordinate studies were carried out as described earlier.

Because of the large number of conformations possible with structures of this size, a full investigation of the trifluoro-1:1 adduct was carried out in the form of separate reaction coordinate studies about each of the bonds labeled in Fig. 4.

It was clear from the reaction coordinate studies about the side chain that our optimized geometry for the trifluoro-1:1 adduct was not in the most stable conformation. A detailed conformational study of the $-\mathrm{O}-\mathrm{CO}-\mathrm{OH}$ side chain was then carried out. This was investigated by fully optimizing the seven possible conformations obtained from $180^{\circ}$ rotations of the side chain in all combinations one bond at a time. The cases examined are shown in Scheme 2.

The conformation labeled (b) was found to give the lowest total energy upon full optimization. The increased stability $(23.6 \mathrm{~kJ} / \mathrm{mol})$ of conformer $(\mathbf{b})$ compared to our original optimized structure may be attributed to hydrogen bonding, since the distance between

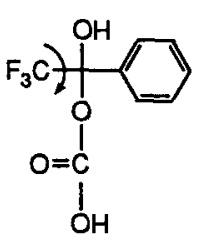

(i)

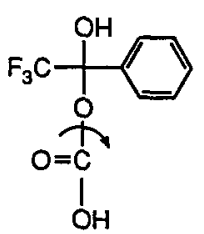

(iv)

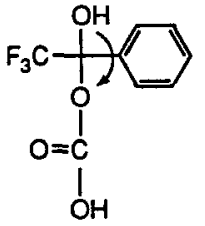

(ii)

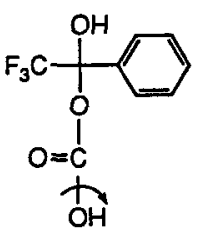

(v)

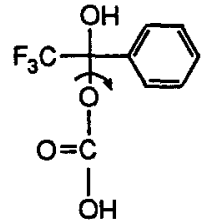

(iii)

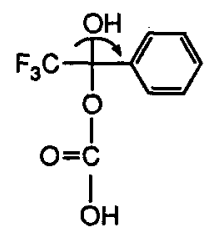

(vi)
Fig. 4. Various bond rotations examined for the trifluoro-1: 1 adduct.

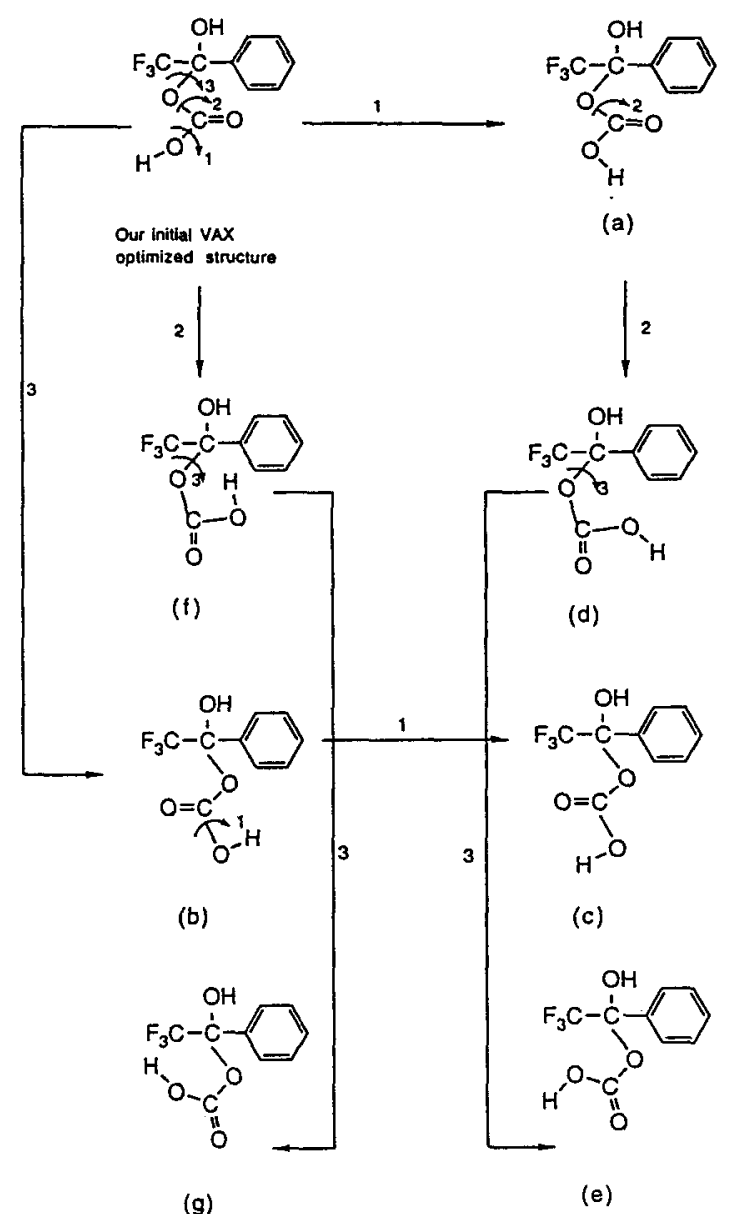

Scheme 2. Schematic representation of the $-\mathrm{O}-\mathrm{CO}-\mathrm{OH}$ sidechain rotations for the trifluoro-1:1 adduct. Numbers along the arrows represent the respective bond rotations. 


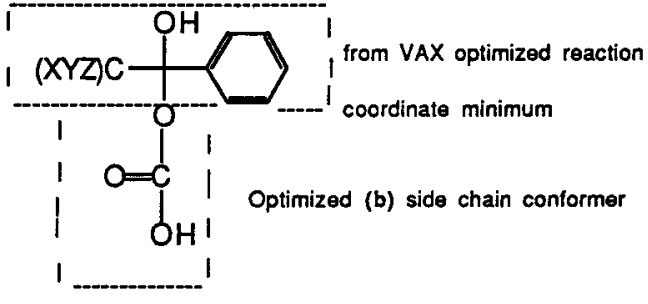

Fig. 5. Source of initial conformation for the $1: 1$ adducts.

the hydroxy group adjacent to the phenyl and the carbonyl oxygen of the side chain for this conformer was only $2.1 \AA$, compared to our original otpimized structure, for which the distance was $4.46 \AA$.

Due to the impossibility of testing all possible conformations on a multidimensional energy hypersurface such as exists for a molecule with a large number of degrees of freedom, a strategy was decided upon. As a new starting geometry for optimization, we appended the coordinates of the optimized side-chain conformer (b) (which we had found to be the most stable) to the optimized minimum-energy conformer from our reaction coordinate studies of rotation about the $(\mathrm{XYZ}) \mathrm{C}-\mathrm{C}$ bond. This is shown in Fig. 5 and was carried out for each halogen derivative of the $1: 1$ adduct. These structures were then further optimized for consistency. No test was made for the lowest energy conformation of the hydroxy group adjacent to the phenyl ring.

Carbonic acid, $\mathrm{H}_{2} \mathrm{CO}_{3}$, which gave a calculated total energy of $-107,878.0 \mathrm{~kJ} / \mathrm{mol}$, is constant for each reaction and included in our calculation of total energy differences given in Table IV. A similar trend to that for the reaction with water is seen. Again it is clear that the fluorine derivatives give a lower total energy difference between products and rectants compared to the chlorine

Table IV. AM1 Calculated Total Energy Differences for the Reaction of $\mathrm{H}_{2} \mathrm{CO}_{3}$ with the Halogen Derivatives of Acetophenone ${ }^{a}$

\begin{tabular}{clc}
\hline Reaction & Substituent & $\begin{array}{c}\text { Total energy difference } \\
\text { (products }- \text { reactants) } \\
(\mathrm{kJ} / \mathrm{mol})\end{array}$ \\
\hline 8 & $\mathrm{~F}_{3} \mathrm{C}-$ & -14.2 \\
9 & $\mathrm{~F}_{2} \mathrm{HC}-$ & -16.4 \\
10 & $\mathrm{FH}_{2} \mathrm{C}-$ & -18.2 \\
11 & $\mathrm{H}_{3} \mathrm{C}-$ & -15.0 \\
12 & $\mathrm{Cl}_{3} \mathrm{C}-$ & -2.7 \\
13 & $\mathrm{Cl}_{2} \mathrm{HC}-$ & -2.3 \\
14 & $\mathrm{ClH}_{2} \mathrm{C}-$ & -11.6 \\
\hline
\end{tabular}

${ }^{a}$ In each case the most stable conformer found was used in calculating these differences. derivatives, but the order of relative stability within the fluorine and chlorine derivatives is unexpected. Also, the observed relative stability of the product for the reaction of carbonic acid with acetophenone (the $-\mathrm{CH}_{3}$ derivative) in relation to the fluorine and chlorine derivatives in Table IV is unusual.

\section{Reaction of Halogen Derivatives of Acetophenone with Bicarbonate Anion}

The addition of $\mathrm{HCO}_{3}{ }^{-}$to the halogen derivatives of acetophenone was also examined (Table V). We shall refer to these products as the halogen derivatives of the $1: 1$ adduct anions. As for the neutral $1: 1$ adduct derivatives, reaction coordinate studies were carried out with the $1: 1$ adduct anions about the $(\mathrm{XYZ}) \mathrm{C}-\mathrm{C}$ bond to substantiate whether or not the most stable conformer has been found as a result of the optimization.

The $1: 1$ adduct anions posed similar problems to the neutral $1: 1$ adducts with regard to the flexibility of the side chain. An identical procedure was used to determine the lowest energy conformer of the molecule. Using the optimized trifluoro-1:1 adduct anion as a starting structure, the three additional conformations obtained from $180^{\circ}$ rotations of the side chain in all combinations, one bond at a time, were examined. These are shown in Scheme 3.

The initial optimized trifluoro-1:1 adduct anion and conformer (a) had identical total energy, as did conformers (b) and (c). This one would expect due to delocalization of the electrons. Conformers (b) and (c) were found to have the lowest energy upon full optimization. This was presumably due to hydrogen bonding. The strategy for determining the lowest energy conformation was then analogous to that used for the neutral

Table V. Reaction of the Halogen Derivatives of Acetophenone with Bicarbonate Anion

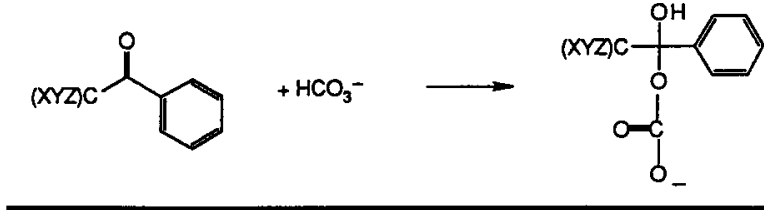

\begin{tabular}{lccc}
\hline Substituent $(X Y Z) C-$ & Reactant & Reaction no. & Product \\
\hline $\mathrm{F}_{3} \mathrm{C}$ & $\mathbf{1}$ & 15 & $\mathbf{2 2}$ \\
$\mathrm{HF}_{2} \mathrm{C}$ & $\mathbf{3}$ & 16 & $\mathbf{2 3}$ \\
$\mathrm{H}_{2} \mathrm{FC}$ & $\mathbf{5}$ & 17 & $\mathbf{2 4}$ \\
$\mathrm{H}_{3} \mathrm{C}$ & $\mathbf{7}$ & 18 & $\mathbf{2 5}$ \\
$\mathrm{Cl}_{3} \mathrm{C}$ & $\mathbf{9}$ & 19 & $\mathbf{2 6}$ \\
$\mathrm{HCl}_{2} \mathrm{C}$ & $\mathbf{1 1}$ & 20 & $\mathbf{2 7}$ \\
$\mathrm{H}_{2} \mathrm{ClC}$ & $\mathbf{1 3}$ & 21 & $\mathbf{2 8}$
\end{tabular}




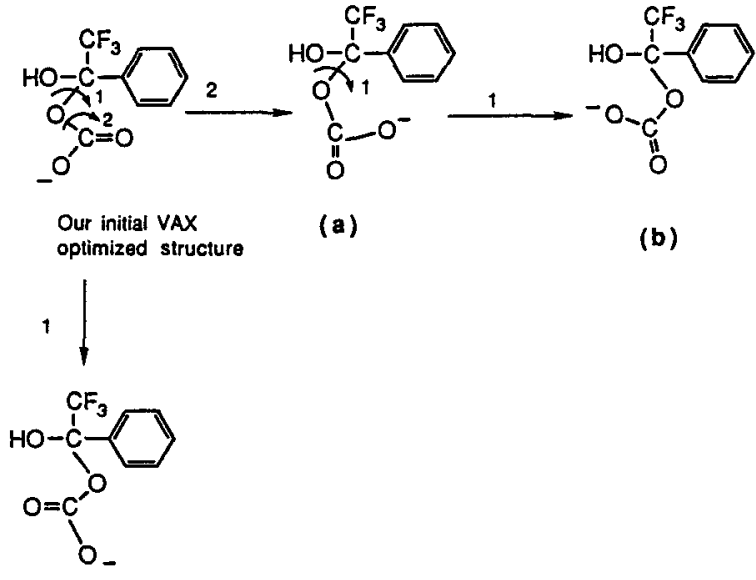

(c)

Scheme 3. Schematic representation of the $-\mathrm{O}-\mathrm{CO}-\mathrm{O}^{-}$side-chain conformations for the trifluoro- $1: 1$ adduct anion. Numbers along the arrows represent the respective bond rotations.

1:1 adducts. The coordinates of the optimized anion side-chain conformer (c) were appended to that of the optimized minimum (for the remaining part of the molecule) from our reaction coordinate studies, as shown in Fig. 6. This was carried out for each halogen derivative of the $1: 1$ adduct anions. For consistency, reoptimization followed.

The bicarbonate anion $\mathrm{HCO}_{3}{ }^{-}$, which gives a calculated total energy of $-106,685.6 \mathrm{~kJ} / \mathrm{mol}$, is included in our calculation of the differences in Table VI. Halogen substitution is clearly favorable in increasing the relative stability of the product. The order within the fluorine derivatives is what we would expect; however, the order for the chlorine derivatives is surprising.

\section{Reaction of the Para-Substituted Derivatives of TFAB with Water and Carbonic Acid}

The effect of various substituents in the para position has been studied for the hydration reactions (22)(25) shown in Table VII. Para-substituted methyl-TFAB

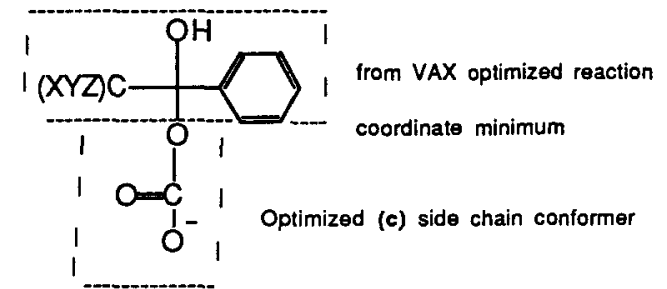

Fig. 6. Source of initial conformation for the 1:1 adduct anions.
Table VI. AMI Calculated Total Energy Differences Between Reactants and Products for the Reaction of $\mathrm{HCO}_{3}^{-}$with the Halogen Derivatives of Acetophenone

\begin{tabular}{clc}
\hline Reaction & Substituent & $\begin{array}{c}\text { Total energy difference } \\
\text { (products - reactants) } \\
(\mathrm{kJ} / \text { mol) }\end{array}$ \\
\hline 15 & $\mathrm{~F}_{3} \mathrm{C}-$ & -74.2 \\
16 & $\mathrm{~F}_{2} \mathrm{HC}-$ & -62.6 \\
17 & $\mathrm{FH}_{2} \mathrm{C}-$ & -48.8 \\
18 & $\mathrm{H}_{3} \mathrm{C}-$ & -29.2 \\
19 & $\mathrm{Cl}_{3} \mathrm{C}-$ & -50.4 \\
20 & $\mathrm{Cl}_{2} \mathrm{HC}-$ & -60.3 \\
21 & $\mathrm{ClH}_{2} \mathrm{C}-$ & -48.0 \\
\hline
\end{tabular}

"In each case the most stable conformer was used in calculating these differences.

Tabie VII. Hydration Reaction for the Para-Substituted Derivatives of Trifluoroacetophenone

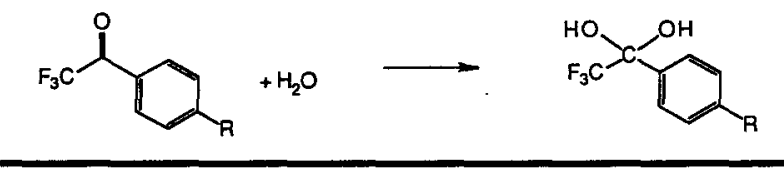

\begin{tabular}{lccc}
\hline $\begin{array}{c}\text { Para } \\
\text { substituent R }\end{array}$ & Reactant & Reaction no. & Product \\
\hline$-\mathrm{CH}_{3}$ & 29 & 22 & 30 \\
$-\mathrm{OCH}_{3}$ & 31 & 23 & 32 \\
$-\mathrm{N}\left(\mathrm{CH}_{3}\right)_{2}$ & 33 & 24 & 34 \\
$-\mathrm{CO}-\mathrm{OCH}_{3}$ & 35 & 25 & 36 \\
\hline
\end{tabular}

29 optimized to the apparent global minimum in which both the phenyl and carbonyl groups lie in the plane. This was also the case for the other para derivatives 31 , 33, and $\mathbf{3 5}$ studied. Reaction coordinate studies were not carried out for the dihydroxy-TFAB derivatives.

The calculated results for the hydration reaction (cf. Table VIII) indicate that an electron-withdrawing substituent in the para position on TFAB gives a lower total energy differences for the reaction, in our case relative to unsubstituted TFAB (total energy difference for the hydration reaction was $-56.8 \mathrm{~kJ} / \mathrm{mol}$ ).

These calculated results are in accordance with the experimental results of Behringer et al. [7] in our laboratory, who showed that a strong electron acceptor in the para position of trifluoroacetophenones increases their preference for carbonate over other anions in comparison to the original TFAB. In this paper [7], the Hammett substituent constant $\sigma$, which is a measure of electron donation or acceptance, was correlated with selectivity and the percent hydration of the ligand in the 
Table VIII. AM1 Calculated Total Energy Differences Between Reactants and Products for the Reaction of Water with the Para Derivatives of Trifluoroacetophenone (TFAB) ${ }^{a}$

\begin{tabular}{lcc}
$\begin{array}{c}\text { Para } \\
\text { substituent } \mathrm{R}\end{array}$ & Reaction & $\begin{array}{c}\text { Total energy difference } \\
\text { (product }- \text { reactants) } \\
\text { (kJ/mol) }\end{array}$ \\
\hline$-\mathrm{CH}_{3}$ & 22 & -55.9 \\
$-\mathrm{OCH}_{3}$ & 23 & -54.6 \\
$-\mathrm{N}\left(\mathrm{CH}_{3}\right)_{2}$ & 24 & -51.7 \\
$-\mathrm{CO}-\mathrm{OCH}_{3}$ & 25 & -59.9 \\
$-\mathrm{H}$ & 1 & -56.8 \\
\hline
\end{tabular}

${ }^{a}$ The calculated total energy of water of $-33,631.1 \mathrm{~kJ} / \mathrm{mol}$ was included.

membrane. Better selectivities for carbonate over chloride were obtained for ligands with substituents of high $\sigma$ values. These are the ligands 6-8 in Table IX. Since 6 exhibits the highest lipophilicity, it is the most favorable ligand.

Our results (cf. Table VIII) show the expected trend in terms of the electron-withdrawing or electron-donating strength of the phenyl substituents. A methyl group, which is only weakly electron-donating, gives a lower total energy difference for the hydration reaction than the moderately strongly electron-donating methoxy group. Similarly, the reaction in which there is a methoxy substituent on the aromatic ring gives a lower energy difference for the reaction than that in which there

Table IX. Para-Substituted Trifluoroacetophenones Listed with the Corresponding Substituent Constants and Lipophilicities [7]

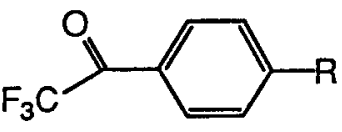

\begin{tabular}{lcc}
\hline Para substituent $R$ & Substituent constant & Lipophilicity \\
\hline $\mathrm{C}_{7} \mathrm{H}_{15}$ & & \\
$\mathbf{N}$ & -0.60 & 7.0 \\
$\mathbf{C}$ & & \\
$2-\mathrm{O}-\mathrm{C}_{3} \mathrm{H}_{17}$ & -0.34 & 7.0 \\
$3-\mathrm{C}_{12} \mathrm{H}_{25}$ & -0.16 & 9.6 \\
$4-\mathrm{S}-\mathrm{C}_{12} \mathrm{H}_{25}$ & -0.05 & 9.7 \\
$\mathrm{C} / 2 \mathrm{H}_{25}$ & & \\
$5-\mathrm{N}$ & -0.02 & 6.7 \\
$-\mathrm{COCH}$ & & \\
$6-\mathrm{CON}_{3}\left(\mathrm{C}_{8} \mathrm{H}_{17}\right)_{2}$ & 0.36 & 8.0 \\
$7-\mathrm{COOC}_{7} \mathrm{H}_{15}$ & 0.52 & 5.2 \\
$8-\mathrm{SO}_{2} \mathrm{Cl}_{2} \mathrm{H}_{25}$ & 0.73 & 5.0 \\
\hline
\end{tabular}

is a more strongly electron-donating tertiary amino group.

As the total energy differences in Table VIII show, the electron-withdrawing ester group $-\mathrm{CO}-\mathrm{OCH}_{3}$ is the most favorable for the reaction in terms of providing the lowest total energy difference for the reaction. Although no test was made to ensure that the para-substituted side chains were in the lowest possible conformation, all reaction coordinate studies about the $\mathrm{F}_{3} \mathrm{C}-\mathrm{C}$ bond for the TFAB derivatives were carried out with full optimization of these side-chain coordinates. A plot of our total energy differences versus sigma, Hammett's substituent constant (cf. Fig. 7), gave a good linear correlation for the following sigma values listed in parentheses (along with corresponding references) for various para substituents: $-\mathrm{CH}_{3}(-0.170)$ [8], $-\mathrm{OCH}_{3}$ $(-0.268)[8],-\mathrm{N}\left(\mathrm{CH}_{3}\right)_{2}(-0.83)[8],-\mathrm{CO}-\mathrm{OCH}_{3}$ (0.39) [9].

A comparison between the effects of the electrondonating methyl group and the more strongly electrondonating methoxy group was made for the reaction involving the addition of carbonic acid to para-substituted methyl- and methoxy-TFAB. (Scheme 4). Tests were not made to substantiate if these were the lowest energy conformers; however, the results (Table $\mathrm{X}$ ) show the expected trend and again indicate that the more strongly electron-donating methoxy group brings about a decrease in susceptibility to nucleophilic attack of the parasubstituted TFAB derivatives when compared to the more weakly electron-donating methyl group. Simi-

Total Energy Diff. versus Sigma

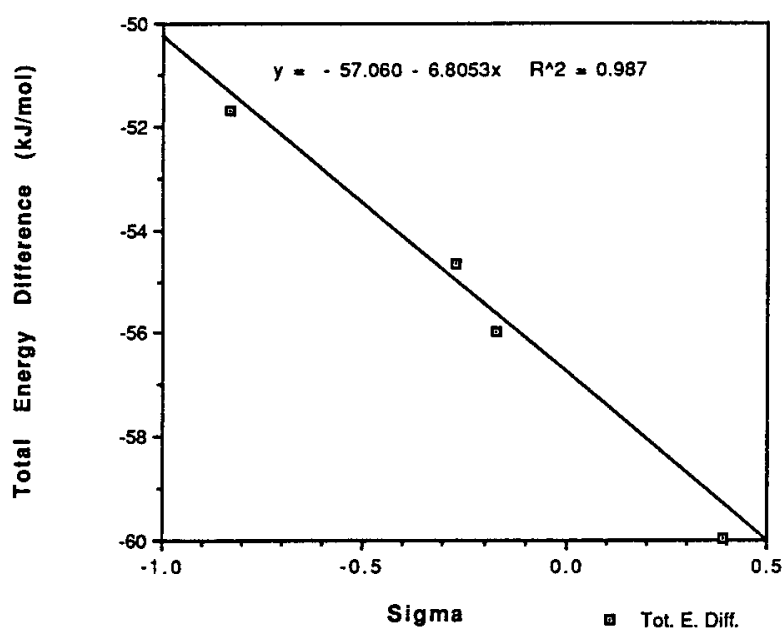

Fig. 7. Graph of calculated total energy differences (for the reaction of water with the para-substituted derivatives of TFAB) versus the substituent constant sigma. 


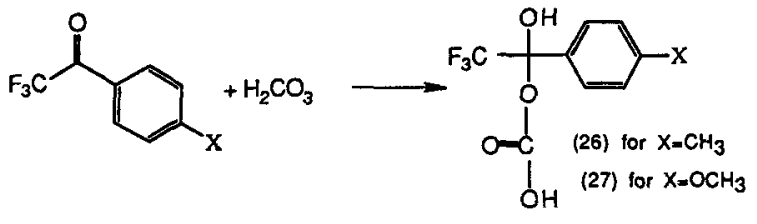

$$
\begin{aligned}
& 29\left(\mathrm{X}=\mathrm{CH}_{3}\right) \\
& \text { 31. }\left(\mathrm{X}=\mathrm{OCH}_{3}\right) \\
& 37\left(\mathrm{X}=\mathrm{CH}_{3}\right) \\
& 38\left(\mathrm{X}=\mathrm{OCH}_{3}\right)
\end{aligned}
$$

Scheme 4. Reaction of para-substituted methyl-TFAB and methoxyTFAB with carbonic acid.

Table X. AM1 Calculated Total Energy Differences Between Reactants and Products for the Reaction of Carbonic Acid with the Para Derivatives of Trifluoroacetophenone (TFAB) ${ }^{a}$

\begin{tabular}{lcc}
\hline $\begin{array}{c}\text { Para } \\
\text { substituent R }\end{array}$ & Reaction & $\begin{array}{c}\text { Total energy difference } \\
\text { (products - reactants) } \\
(\mathbf{k J} / \text { mol) }\end{array}$ \\
\hline$-\mathrm{CH}_{3}$ & 26 & -13.5 \\
$-\mathrm{OCH}_{3}$ & 27 & -12.0 \\
$-\mathrm{H}$ & 8 & -14.2 \\
\hline
\end{tabular}

"The calculated total energy of carbonic acid of $-107,878.0 \mathrm{~kJ} / \mathrm{mol}$ was included.

larly, the methyl group brings about a decrease in susceptibility to nucleophilic attack of the para-substituted TFAB derivatives relative to the analogous reaction involving the unsubstituted trifluoro-1:1 adduct (total energy difference for reaction $=-14.2 \mathrm{~kJ} / \mathrm{mol}$ ).

Comparing the results of the reaction with carbonic acid and to those of the reaction with water was of interest, as this has a practical relevance. Hydration is a competitive reaction to carbonate binding. The energy difference between these two reactions for the para methyl substituent $(42.4 \mathrm{~kJ} / \mathrm{mol})$ is comparable to that for the para methoxy substituent $(42.6 \mathrm{~kJ} / \mathrm{mol})$ within the limits of accuracy. Variation of the para substituent therefore has no effect on the selectivity. As the binding to carbonic acid increases, the binding to water also increases.

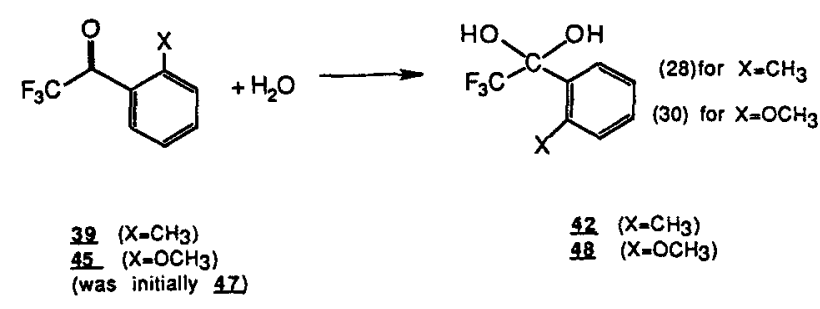

Scheme 5. Hydration reaction of the ortho-monosubstituted methyl and methoxy derivatives of TFAB.

\section{Ortho-Substituted Derivatives of TFAB and Hydrated TFAB}

The effects of ortho substitution on the total energy difference between reactants and products of the reactions (28)-(31) were investigated (Schemes 5 and 6). In calculating the energy differences (Table XI), the most stable conformer of the reactants and products in terms of total energy was selected in each case.

The influence of a methyl group, a weakly electron-donating group, and methoxy, a more strongly electron-donating group, in the ortho position was studied. The case in which the ortho-substituted methyl (methoxy) group lies cis to the carbony group initially in structure 39 (45), with the phenyl and carbonyl group in the same plane, is referred to as the -omethyl 1 (-omethoxy 1) structure. Similarly, 47 (47) is referred to as the -omethyl 2 (-omethoxy 2) structure (Fig. 8). The disubstituted-odimethyl (-odimethoxy) structure $\mathbf{4 3}$ (49) was also studied.

Reaction coordinate studies involving rotation about the $\mathrm{F}_{3} \mathrm{C}-\mathrm{C}$ bond were carried out for each structure to check that the optimized geometry of the $\mathrm{F}_{3} \mathrm{C}-$ moiety was in its lowest energy conformation. There is, however, no certainty with the results presented that the remainder of the molecule is in its most stable conformation or that the ortho substituents have the same conformation in the reactants and products.

Furthermore, visualization on a graphics system showed for the -omethyl 2 derivative that repulsive interaction between the $\mathrm{F}_{3} \mathrm{C}$ - and methyl groups has

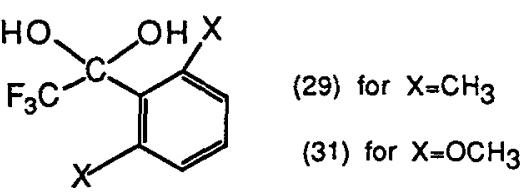

$$
\begin{array}{ll}
\frac{44}{50} & \left(\mathrm{X}=\mathrm{CH}_{3}\right) \\
& \left(\mathrm{X}=\mathrm{OCH}_{3}\right)
\end{array}
$$

Scheme 6. Hydration reaction of the ortho-disubstituted methyl and methoxy derivatives of TFAB. 
Table XI. AMI Calculated Total Energy Differences Between Reactants and Products for the Reaction of Water with the Ortho Derivatives of Trifluoroacetophenone (TFAB) ${ }^{a}$

\begin{tabular}{cc}
\hline Reaction & $\begin{array}{c}\text { Total energy difference (products - reactants) } \\
(\mathrm{kJ} / \mathrm{mol})\end{array}$ \\
\hline 28 & -54.9 \\
29 & -49.1 \\
30 & -64.5 \\
31 & -52.0 \\
1 & -56.8 \\
\hline
\end{tabular}

${ }^{a}$ The calculated total energy of water as a reactant $(-33,631.1 \mathrm{~kJ} /$ mol) is included.

caused the phenyl group to rotate, so that the methyl group is now on the same side as the carbonyl group for the minimum-energy conformation. Although the starting conformation of the methyl group with respect to the $\mathrm{F}_{3} \mathrm{C}$ - group was not ideal, one would expect correlated motion of these two rotamers to find a more suitable conformation if it were possible. Instead, the -omethyl 2 position is clearly unfavorable due to the repulsive interaction. Visualization of the -omethoxy 2 derivative showed that, as for the -omethyl 2 derivative, repulsive interaction between the $\mathrm{F}_{3} \mathrm{C}-$ and methoxy groups has caused the phenyl group to rotate, so that the methoxy group is now cis to the carbonyl group for the lowest energy conformation.

In the hydrated TFAB case, the -omethyl 1 (-omethoxy 1), -omethyl 2 (-omethoxy 2), and -odimethyl (-odimethoxy) have the same relative positions on the phenyl ring as was the case for the TFAB.

The structures shown in the reactions (Schemes 5 and 6) represented the most stable conformers found and these were the reactions considered in calculating the overall total energy differences listed in Table XI. Structure 47 (which initially had the methoxy group trans to the carbonyl group) is represented in Scheme 5 with the methoxy group cis to the carbonyl group, as this was found to be the most stable conformation following reoptimization of the reaction coordinate minimum.

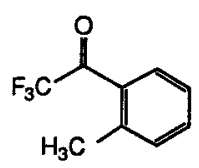

41

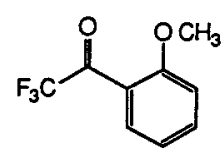

4.5

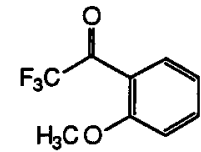

47
Fig. 8. Other ortho derivatives of trifluoroacetophenone.
The total energy differences given in Table XI show that despite the electron-donating influence of a methoxy group, monosubstitution in a favorable conformation affords a significant degree of stabilization when compared to that of the reaction of unsubstituted TFAB with water (total energy difference of $-56.8 \mathrm{~kJ} / \mathrm{mol}$ ). Both electronic and steric effects play a role in the case of the ortho derivatives. Visualization indicates that this stabilization is possibly brought about by hydrogen bonding between a hydroxy group and the oxygen atom of the methoxy group, the distance between these being $2.093 \AA$.

\section{CONCLUSION}

There is a clear preference for fluorine rather than chlorine derivatives in the reactions of the acetophenone derivatives with water and those with carbonic acid. In the case of the reaction with bicarbonate anion these differences between fluorine and chlorine derivatives are not so clearly defined. Such energy differences are close in value for the reactions, it is difficult to draw conclusions as to the effect of degree of halogen substitution.

Stability of the monofluoro-derivatives in comparison with that of the trichloro- acetophenone derivatives for the reaction with carbonic acid and also for the hydration reaction was indicated. This, however, was not the case for the reaction with the bicarbonate anion.

In the case of the para-substituted derivatives of trifluoroacetophenone, an electron-withdrawing substituent such as an ester group in the para position appeared to bring about stability. Variation of the para substituent had no effect on the selectivity, however, when the reaction with carbonic acid was compared to the hydration reaction, since an increase in binding to carbonic acid resulted in a similar increase in the binding to water.

A monosubstituted ortho methoxy group appeared to bring about stability, possibly due to hydrogen bonding for the hydration reaction of trifluoroacetophenone.

\section{ACKNOWLEDGMENTS}

J.M.I. is indebted to the late Prof. W. Simon for the opportunity to work in his research group at the ETH Zurich, as well as to her advisor Prof. E. Pretsch. Further thanks go to Dr. J. Hutter, formerly of the supercomputer center, ETH, for his helpful discussions concerning the research work, and Prof. E. Roduner, University of Stuttgart (formerly of Zurich University), 
for his critical reading and suggestions. Dr. A. Furst is thanked for his program to allow visualization of the output. A generous grant of computer time provided by the computer center of the ETH Zurich is gratefully acknowledged.

\section{REFERENCES}

1. Meyerhoff, M. E.; Pretsch, E.; Welti, D.; Simon, W. Anal. Chem. $1987,59,144-150$.
2. Behringer, C.; Lehmann, B.; Simon, W. Chemia 1987, 41(11), 397-398.

3. Dewar, M. J. S.; Zoebisch, E. G.; Healy, E. F.; Stewart, J. J. P. J. Am. Chem. Soc. 1985, 107, 3902-3909.

4. Mollendal, H. Acta Chem. Scand. 1972, 26(9), 3804-3806.

5. Hilderbrandt, R. L.; Andreassen, A. L.; Bauer, S. H. J. Phys. Chem. 1970, 74, 1586-1592.

6. Bürgi, H.-B.; Dubler-Steudle, K. C. J. Am. Chem. Soc. 1988, 110, 7291-7299.

7. Behringer, C.; Lehmann, B.; Haug, J.-P.; Seiler, K.; Morf, W.; Hartman, K.; Simon, W. Anal. Chim. Acta 1990, 233, 41-47.

8. McDaniel, D. H.; Brown, H. C. J. Org. Chem. 1958, 23, 420427.

9. Barlin, G. B.; Perrin, D. D. Q. Rev. 1966, 20, 75-101. 